\title{
Load Transfer Test of Post-Tensioned Anchorage Zone in Ultra High Performance Concrete
}

\author{
Jee-Sang Kim¹, Changbin Joh², Yoon-Seok Choi ${ }^{3}$ \\ ${ }^{1}$ Department of Civil \& Architectural Engineering, Seokyeong University, Seoul, The Republic of Korea \\ ${ }^{2}$ Structural Engineering Research Division, Korea Institute of Construction Technology, Goyang, The Republic of \\ Korea \\ ${ }^{3}$ TM Enc Research Institute, Seoul, The Republic of Korea \\ Email: zskim@skuniv.ac.kr, cjoh@kict.re.kr, cyschoi87@naver.com
}

Received 2 March 2015; accepted 20 March 2015; published 24 March 2015

Copyright (C) 2015 by authors and Scientific Research Publishing Inc.

This work is licensed under the Creative Commons Attribution International License (CC BY).

http://creativecommons.org/licenses/by/4.0/

(c) (i) Open Access

\section{Abstract}

Researches on ultra-high performance concrete (UHPC) have been conducted worldwide owing to its outstanding durability and strength performances. The exploitation of the mechanical properties of UHPC will render it possible to achieve economic design through substantial reduction in the cross sectional dimensions and simplification in the reinforcement arrangement. This paper investigates experimentally the load transfer in the prestressed concrete anchorage zone. To provide distinctive features of UHPC compared to ordinary concrete, the cross sectional dimensions of the member were reduced and the stress distribution, deformation and cracking pattern of the PS anchorage zone were examined experimentally according to the degree of reinforcement of the members chosen. The distributions of the bursting stress, spalling stress and longitudinal edge stress in the specimens were observed according to the various types of reinforcement. All the specimens satisfied the load-bearing capacity criterion specified by the European ETAG-013 guidelines and their stress distributions were similar to those in the PS anchorages of post-tensioned members applying ordinary concrete. The cracks propagated longitudinally with lengths up to twice the cross sectional dimensions and their width was smaller than when applying ordinary concrete owing to the bridging effect of the steel fibers in UHPC. Accordingly, the exploitation of the high strength of UHPC enabled us to secure the resistance of the anchorage with no need for particular reinforcing devices.

\section{Keywords}

UHPC, PS Anchorage Zone, Load Transfer Test, Bursting Force, Splitting Force 


\section{Introduction}

Worldwide researches have been extensively implemented for the development of high performance concrete (HPC) in a will to improve and enhance the performance of ordinary concrete. Especially, the designation of ultra-high performance concrete (UHPC) was attributed to the new material exhibiting substantially improved performance compared to the previous HPC and distinguished it from HPC [1]. France, Germany, USA and Japan undertook systematic researches on UHPC and obtained numerous outcomes [2]-[6]. In Korea, the Korea Institute of Construction Technology (KICT) also achieved world-level research outcomes through the development of its own UHPC exhibiting high ductility, toughness and durability with a compressive strength of $200 \mathrm{MPa}$ and tensile strength of $13 \mathrm{MPa}$ [7]. In addition, KICT has undertaken the design of a PSC cable-stayed bridge using UHPC and has achieved the preliminary design of several bridges.

In the design and analysis of post-tensioned PSC members using ordinary concrete, full understanding of the long-term behavior like drying shrinkage and creep within the overall behavior of the structure including flexure, shear and torsion and understanding the design of the anchorage is primordial. Especially, in the PSC member made of ordinary concrete, the prestressing tendon is tensioned and fixed in the anchorage zones, of which the reinforcement details are decisive in the design of the cross sectional dimensions of the member. These reinforcement details involve the dense arrangement of steel for resisting to the bursting stress and controlling the cracks in the anchorage zones and induce the problem of enlarging the cross section at the anchorage compared with the other sections of the girder to secure the distance between the anchorages and the clearance with the free end as well as to cope with the occurrence of large bearing stresses. Therefore, the application of UHPC with its remarkable compressive and tensile strength characteristics can offer an attractive solution in reducing effectively the cross sectional dimensions.

Among the studies dedicated to the exploitation of UHPC in PSC structures, Toutlemonde et al. [8] conducted an experimental study on solutions securing the economy and efficiency of the anchorage of UHPC members through the reduction of the confinement steel and the utilization of the bridging effect of the steel fiber. This study verified the possibility to secure adequate safety ratio owing to the outstanding strength characteristics developed by UHPC while reducing substantially the amount of steel and dimensions of cross section.

This paper intends to evaluate the performance of the anchorage zone in prestressed concrete members using the UHPC developed in Korea [7]. To that goal and assess their applicability, specimens without anchorage device and confining re-bars, specimens with anchorage device only and specimens with anchorage and confinement reinforcement were manufactured in compliance with the directives of ETAG-013 [9] (European Technical Agreement Guide No. 13) of the European design codes EOTA to verify the tensile forces, longitudinal displacements and cracking patterns developed in the specimens and evaluate the behavior of the anchorage in the PSC members using UHPC and their degree of safety relative to the design loads in Korean Code (KHBDC 2010) [10].

\section{Test on the Behavior of the Anchorage}

\subsection{Test Variables}

Based upon the research results of Toutlemonde et al. [8], the bridging effect of the steel fibers mixed in UHPC can achieve the confinement effect provided by the lateral confinement reinforcement in the anchorage zones and can be exploited to reduce substantially the amount of confinement steel. Accordingly, this study selected the test variables so as to evaluate the possibility to realize economic design of PSC members by simplifying the reinforcement arrangement details of the anchorage zone, reducing the amount of steel and the cross sectional dimensions of the members with reference to the members using ordinary concrete. Three types of specimens having anchorage zones identical to the traditional post-tensioned one were fabricated to compare their mechanical behaviors with those of ordinary concrete. In order to verify the high strength of UHPC and evaluate its applicability, non-reinforced specimens without anchorage and spiral reinforcement as well as specimens equipped with anchorage but without spiral reinforcement were also manufactured. The specimens applied the K-UHPC developed by KICT [7] of which standard mix proportions are presented in Table 1 . Two mix ratios of $1 \%$ and $2 \%$ were adopted for the steel fiber to evaluate the effect of the mix ratio in steel fiber on the characteristics of the tensile behavior. 


\subsection{Measurement Plan}

The criterion deciding the eventual reinforcement of the anchorage zone is the distribution of the tensile forces in the anchorage zone. The Korean Highway Bridge Design Code, [10], defines the tensile forces acting in the anchorage zone as the bursting force, the spalling force and the longitudinal edge tensile force. Here, the bursting force is the tensile force in the anchorage zone acting transversally to the axis of the tendon, and the edge tensile forces are the tensile forces in the anchorage zone around the longitudinal and lateral edges of the member and acting along these edges. The lateral edge is the face on which the force due to the anchorage applies. In other words, the tensile force acting along the lateral edge is called the spalling force and the tensile force acting along the longitudinal edge is defined as the longitudinal edge tensile force.

The most important objective of the test is to evaluate the magnitudes of the tensile forces and the locations where the maximum tensile forces occur. Kim et al. [11] identified the distribution pattern of the bursting force and the location of the maximum stresses in the anchorage zone of post-tensioned UHPC members by finite element analysis considering the relative size of the anchor plate. These authors reported that the post-tensioned UHPC members behaved similarly to those using ordinary concrete and verified that the maximum bursting stress occurred closer to the loaded face as much as the size ratio of the anchor plate to the cross sectional area of the member increased. This location varied from $0.3 b$ to $0.5 b$ where $b$ is the width of the cross section. Moreover, for locations beyond $1.0 \mathrm{~b}$, the stress converged to a value close to $0 \mathrm{MPa}$ and the loading pattern was seen to have no significant effect. Accordingly, based upon these research results, gages were located at a distance of $10 \mathrm{~mm}$ from the top face as shown in Figure 1 to measure the tensile forces acting on the top face. Gages were also installed at $0.3 b, 0.5 b$ and $1.0 b$ to verify the stress distribution. Crack gages were disposed at $0.3 b$ and $0.5 b$ on both left and right sides of the specimens to measure the width of the cracks induced by the bursting force. Two sets of displacement transducers were also installed symmetrically at the top and bottom faces to measure the overall displacement of the specimens (see Figure 2).

\section{Table 1. Standard mix proportions of K-UHPC [7].}

\begin{tabular}{cccccccc}
\hline Constituent & W/B & Cement & Silica fume & Filler & Fine aggregates & Water-reducing agent & Steel fiber \\
\hline $\begin{array}{c}\text { Weight ratio to } \\
\text { cement content }\end{array}$ & 0.2 & 1 & 0.25 & 0.3 & 1.1 & 0.016 & $2 \%$ (volume fraction) \\
\hline
\end{tabular}

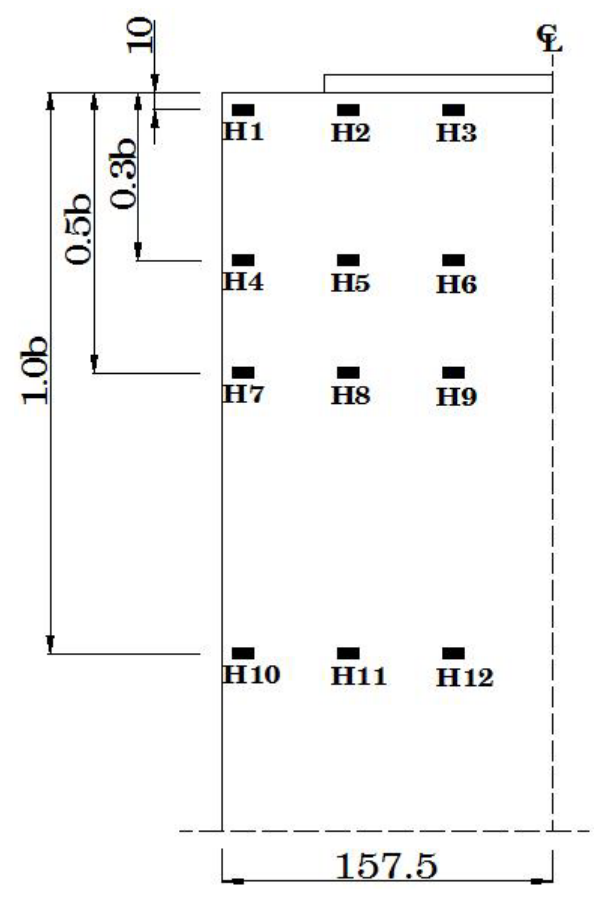

Figure 1. Layout of sensors. 


\subsection{Fabrication of Specimens}

The specimens were fabricated by applying 3 test variables with reference to the standard mix proportions of K-UHPC listed in Table 1 with $1 \%$ and $2 \%$ volume fraction of steel fiber. The smallest commercially available anchorage was used to verify the eventual reduction of the cross sectional dimensions made possible by the bridging effect of the steel fiber in UHPC. The adopted tension anchorage presents monolithically combined anchor and plate. Based upon the results of Kim et al. [11], the cross sectional dimensions were set as $315 \mathrm{~mm}$ considering the size of $215 \mathrm{~mm}$ of the anchor plate and minimum edge clearances of $50 \mathrm{~mm}$ on both sides. Since Toutlemonde et al. [8] reported that the height of the specimen should be at least twice longer than the width of the cross section, the height of the specimens was set to 4 times the width $(1260 \mathrm{~mm})$ so as to have sufficient margin. Figure 3 presents the specimens according to the various reinforcement types.

To simulate real cast-in-place conditions for the specimens, the fabrication of the specimens was conducted by laying the forms transversally and starting placing from the real bottom toward the top using steel forms. The air content and flow were measured to be respectively $21 \%$ and $210 \mathrm{~mm}$ on the mean. The curing process was performed through steam curing during 3 days at $90^{\circ} \mathrm{C}$ to develop the initial strength followed by 1 day of atmospheric curing. Compressive strength specimens and direct tensile strength specimens were also manufactured to evaluate the strength characteristics of the material used.

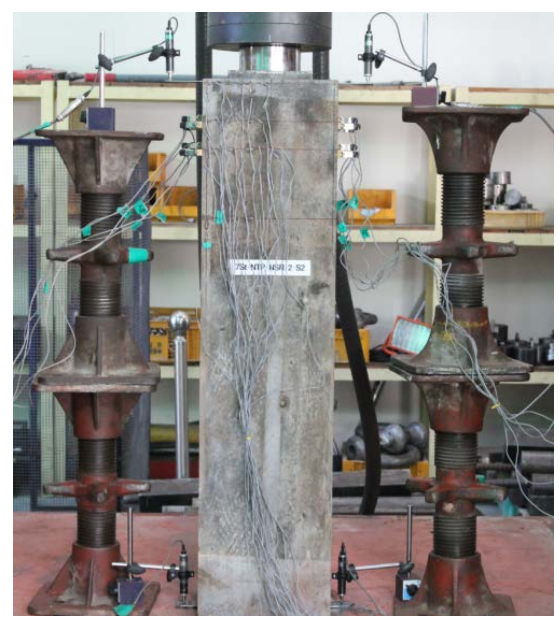

Figure 2. View of specimen.

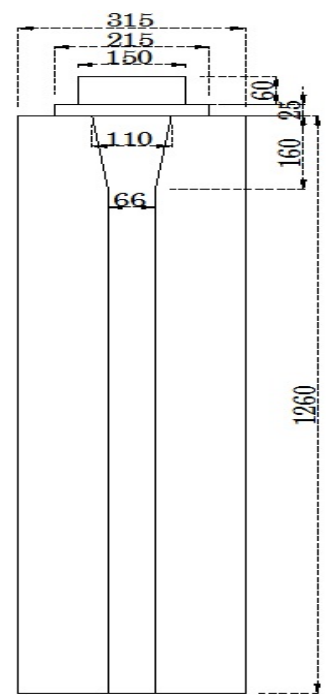

(a) Non-reinforced (NTP-NSR)

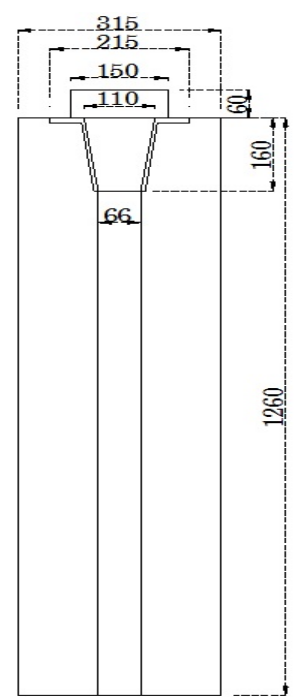

(b) Semi-reinforced (TP-NSR)

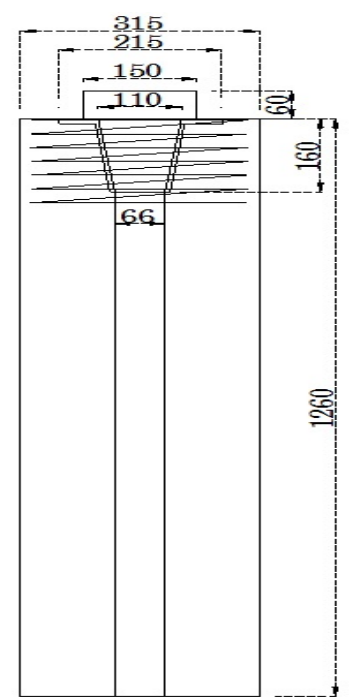

(c) fully reinforced (TP-SR)

Figure 3. Shape and dimensions of specimens according to the type of reinforcement. 


\subsection{Strength Test of UHPC}

\subsubsection{Compressive Strength Test}

In the compressive strength test, three $100 \mathrm{~mm}$-displacement sensors oriented at regular angle of $120^{\circ}$ were installed at the center of the specimens to measure the longitudinal displacement. The elastic modulus in the linear section was computed by Equation (1) using the values of the stress corresponding to $10 \%$ and $30 \%$ of the ultimate compressive strength in the stress-strain curve of the steel fiber-reinforced ultra high strength concrete according to the method proposed by the Federal Highway Agency (FHWA) of USA [1].

$$
E_{c}=\frac{\sigma_{2}-\sigma_{1}}{\varepsilon_{2}-\varepsilon_{1}}
$$

where $\sigma_{1}$ and $\sigma_{2}=$ compressive stresses corresponding to $10 \%$ and $30 \%$ of the ultimate compressive strength; and, $\varepsilon_{1}$ and $\varepsilon_{2}=$ compressive strains corresponding to $\sigma_{1}$ and $\sigma_{2}$.

The mean values of the compressive strength and elastic modulus of the specimen with $1 \%$ of steel fiber are respectively $183 \mathrm{MPa}$ and 46,583 MPa and those of the specimens with 2\% of steel fiber are respectively 177 MPa and 45,939 MPa. Moreover, the standard deviations of the compressive strength and elastic modulus of the specimens with $1 \%$ of steel fiber are respectively 7.5 MPa and $1190 \mathrm{MPa}$ and those of the specimens with $2 \%$ of steel fiber are respectively 5.3 MPa and $2940 \mathrm{MPa}$. The corresponding coefficients of variation are $3 \%$ to $4 \%$ on the mean for the compressive strength and $2 \%$ to $6 \%$ for the elastic modulus, which indicate lower dispersion than in ordinary concrete. Table 2 arranges the experimental values of the tests on compressive strength and elastic modulus.

\subsubsection{Direct Tensile Strength Test}

The direct tensile strength was measured using the test method proposed by KICT [7]. The test makes use of notched test specimens. A UTM (Universal Testing Machine) with capacity of $3000 \mathrm{kN}$ was used to conduct the tensile test through displacement control $(0.2 \mathrm{~mm} / \mathrm{min})$ on the specimens on which a tension jig was disposed at the center. The early crack tensile strength and ultimate tensile strength of the specimen with $1 \%$ of steel fiber are respectively 12.4 MPa and 12.1 MPa, with identical standard deviations of $0.7 \mathrm{MPa}$. For the specimen with $2 \%$ of steel fiber, these values are respectively 11.9 MPa and 13.0 MPa with standard deviation of 2.4 MPa and 1.4 MPa. Such large dispersion in the direct tensile strength can be explained by the fact that the cracks did not occur at the notch prepared to induce cracking. Table 3 arranges the measurement results of the direct tensile test.

\subsection{Test Procedure}

Since there is no approved test method for the PS anchorages using newly developed materials like UHPC, the test was carried out according to the test method prescribed in the ETAG-013 provisions of EOTA which agree at the most with the objective of the test. The test load $\left(\mathrm{F}_{\mathrm{prg}}\right)$ is specified to be larger than the tensile load of 260 $\mathrm{kN}$ of SWPC 7B-15.2 mm (0.6") steel wire in KHBDC [10]. Considering that the adopted anchorage uses 7 steel wires, the test load was set to $1820 \mathrm{kN}$. Loading was applied according to the pattern in Figure 4. The changes in the strain and crack width were measured at each loading stage.

Table 2. Compressive strength and elastic modulus.
\begin{tabular}{|ccccc}
\hline Volume fraction of steel fiber & Compressive strength (MPa) & \multicolumn{3}{l|}{ Elastic modulus (MPa) } \\
\hline & Mean & 183 & Mean & 46,583 \\
$1 \%$ & Std. deviation & 7.2 & Std. deviation & 1190 \\
COV (\%) & 3.7 & COV (\%) & 2.5 \\
Mean & 177 & Mean & 45,939 \\
& Std. deviation & 5.3 & Std. deviation & 2940 \\
& COV (\%) & 3.0 & COV (\%) & 5.7 \\
\hline
\end{tabular}


Table 3. Early-crack strength and ultimate tensile strength.

\begin{tabular}{ccccc}
\hline Volume fraction of steel fiber & \multicolumn{2}{c}{ Tensile strength at early cracking (MPa) } & Ultimate tensile strength (MPa) \\
\hline $1 \%$ & 12.4 & Mean & 12.1 \\
Std. deviation & 0.7 & Std. deviation & Mean & 13.0 \\
Sean & 11.9 & Std. deviation & 1.4 \\
\hline
\end{tabular}

Figure 4. Loading pattern.

\section{Analysis of Test Results}

The tests were conducted on 3 types of specimens manufactured with the mix ratio of steel fiber and the type of reinforcement as variables. For the three non-reinforced specimens, one specimen was tested without loading plate under the assumption that the specimen could exhibit safe behavior even without the loading plate. The designation of the specimens adopted in this section follows the following convention: TP stands for the use of trumpet type anchorage; SR for the use of confinement steel; NTP and NSR indicate the absence of trumpet type anchorage and the absence of confinement reinforcement; the subsequent number indicates the mix ratio of steel fiber in volume fraction; and, the last number designates the serial number of the specimen in the same series. For example, specimen 7St-NTP-NSR-1-S1 designates the first specimen in the series S using 7 steel wires, which does not apply the trumpet-shaped anchorage, without confinement steel and with $1 \%$ of steel fiber. This chapter compares the reinforcement type with respect to the mix ratio in steel fiber so as to analyze the respective stress distribution, failure mode and displacement.

\subsection{Stress Distribution}

\subsubsection{Bursting Forces}

Figure 5 arranges the bursting stress distribution measured by the strain gage at the center of the specimen according to the type of reinforcement and mix ratio of steel fiber. Table 4 presents the values of the bursting stress by comparing their values for the fiber ratios of $1 \%$ and $2 \%$ successively for the non-reinforced (NTPNSR) specimens, semi-reinforced (TP-NSR) specimens and, fully reinforced (TP-SR) specimens.

The comparison of the non-reinforced (NTP-NSR) specimens with $1 \%$ and $2 \%$ of steel fiber shows that there is small difference in the compressive stress at location close to the top (far by $10 \mathrm{~mm}$ from the top) according to the mix ratio of steel fiber with values of $1.50 \mathrm{MPa}$ and 1.48 MPa, that tensile stresses of $8.41 \mathrm{MPa}$ and 6.32 MPa were measured at $0.3 b$ ( $b=$ width of cross section) and values of $8.07 \mathrm{MPa}$ and $9.11 \mathrm{MPa}$ were measured at $0.5 b$. Small change in the stress was observed for $1 \%$ of steel fiber whereas difference larger than 2 MPa occurred for $2 \%$ of steel fiber. The ultimate tensile stress developed at $0.3 b$ for $1 \%$ steel fiber and developed up to 


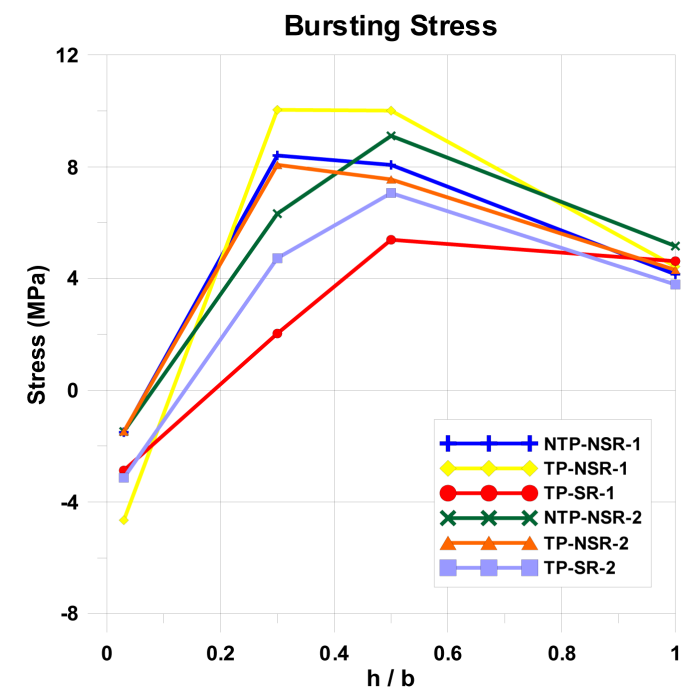

Figure 5. Bursting stress according to applied load.

Table 4. Bursting stresses at diverse locations (in MPa).

\begin{tabular}{ccccccc}
\hline$h / b$ & NTP-NSR-1 & TP-NSR-1 & TP-SR-1 & NTP-NSR-2 & TP-NSR-2 & TP-SR-2 \\
\hline 0.03 & -1.50 & -4.65 & -2.87 & -1.48 & -1.48 & -3.13 \\
0.3 & 8.41 & 10.04 & 2.03 & 6.32 & 8.07 & 4.73 \\
0.5 & 8.07 & 10.01 & 5.39 & 9.11 & 7.55 & 7.06 \\
1 & 4.15 & 4.43 & 4.62 & 5.16 & 4.31 & 3.78 \\
\hline
\end{tabular}

9.11 MPa at $0.5 b$ for $2 \%$ of steel fiber. The tensile stress at $1.0 b$ tended to reduce to half of that at $0.5 b$ and, the size of the stress appeared to decrease rapidly as much as moving downward in the longitudinal direction.

For the semi-reinforced (TP-NSR) specimens, reinforced by trumpet-type anchorage device only without confinement steel, the compressive stresses of 4.65 MPa and 1.48 MPa were measured at location close to the top and showed large difference of $3 \mathrm{MPa}$ according to the mix ratio of steel fiber. The tensile stress at $0.3 \mathrm{~b}$ increased up to $10.04 \mathrm{MPa}$ for $1 \%$ of steel fiber and $8.07 \mathrm{MPa}$ for $2 \%$ of steel fiber, and became respectively 10.01 MPa and 7.55 MPa at $0.5 b$. Similarly to the non-reinforced specimens (NTP-NSR), the stress for $1 \%$ of steel fiber experienced relatively small variation between $0.3 b$ and $0.5 b$. Here, the ultimate tensile stress occurred at $0.3 b$ in both steel fiber ratios of $1 \%$ and $2 \%$. The tensile stress at $1.0 b$ appeared also to reduce to half of that at $0.5 b$ for both mix ratios in steel fiber with values of $4.43 \mathrm{MPa}$ and $4.31 \mathrm{MPa}$, which are similar to the size of the stresses measured in the non-reinforced specimens.

In the case of the fully-reinforced (TP-SR) specimens reinforced by both trumpet-type anchorage device and spiral reinforcement, the compressive stresses near the top were measured to be $2.78 \mathrm{MPa}$ and $3.13 \mathrm{MPa}$ and showed small difference similarly to the non-reinforced specimens. The tensile stresses at $0.3 b$ were $2.03 \mathrm{MPa}$ and 4.73 MPa and became 5.39 $\mathrm{MPa}$ and $7.06 \mathrm{MPa}$ at $0.5 \mathrm{~b}$. The ultimate tensile stress occurred at $0.5 \mathrm{~b}$. The fully reinforced (TP-SR) specimens exhibited a distribution of relatively smaller stresses in concrete compared to the non-reinforced (NTP-NSR) specimens and the specimens using only anchorage (TP-NSR).

\subsubsection{Spalling Forces}

Figure 6 arranges the spalling stress distribution at the location closest to the top according to the type of reinforcement and mix ratio of steel fiber. Table 5 lists the magnitudes of the spalling stress measured at diverse locations. The stress was measured by three transverse gages positioned at distances of $10 \mathrm{~mm}, 60 \mathrm{~mm}$ and $110 \mathrm{~mm}$ from the left-hand side as shown in Figure 1. 


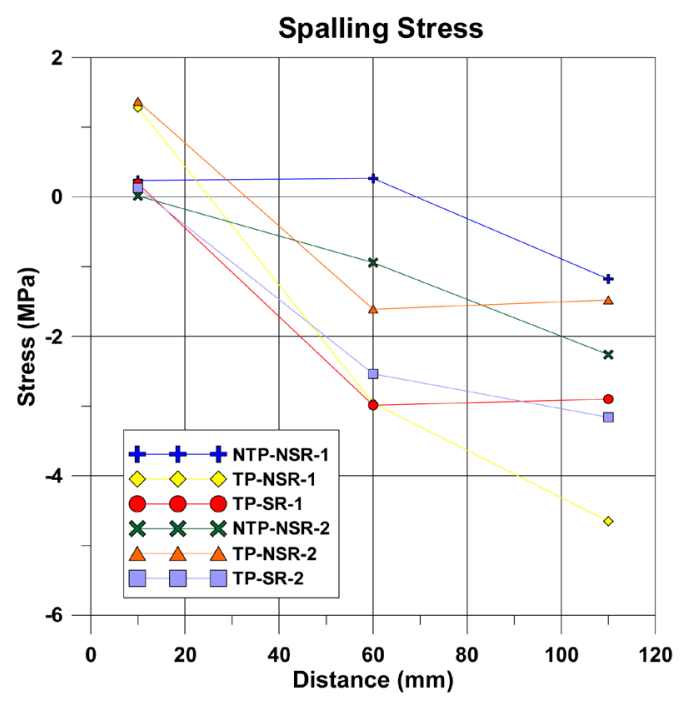

Figure 6. Spalling stresses according to applied load.

Table 5. Spalling stresses at diverse locations (in MPa).

\begin{tabular}{ccccccc}
\hline Distance & NTP-NSR-1 & TP-NSR-1 & TP-SR-1 & NTP-NSR-2 & TP-NSR-2 & TP-SR-2 \\
\hline $10 \mathrm{~mm}$ & 0.24 & 1.28 & 0.19 & 0.01 & 1.37 & 0.13 \\
$60 \mathrm{~mm}$ & 0.26 & -2.96 & -2.99 & -0.94 & -1.61 & -2.54 \\
$110 \mathrm{~mm}$ & -1.18 & -4.65 & -2.90 & -2.26 & -1.48 & -3.16 \\
\hline
\end{tabular}

For the non-reinforced (NTP-NSR) specimens with 1\% and $2 \%$ of steel fiber, the tensile stress at location close to the top (far by $10 \mathrm{~mm}$ from the top) reached $0.24 \mathrm{MPa}$ and $0.01 \mathrm{MPa}$ and showed that there was practically no change in the stress for the non-reinforced specimens with $2 \%$ of steel fiber. The tensile stress distribution at $60 \mathrm{~mm}$ was measured to be $0.26 \mathrm{MPa}(1 \%$ of steel fiber) and $0.94 \mathrm{MPa}$ ( $2 \%$ of steel fiber) and turned onto compressive stresses of $1.18 \mathrm{MPa}$ and $2.26 \mathrm{MPa}$ at $110 \mathrm{~mm}$. Even if the specimens with $1 \%$ and $2 \%$ of steel fiber exhibited similar stress distribution, the difference in the stress at $60 \mathrm{~mm}$ and $110 \mathrm{~mm}$ seems to be induced by cracks invisible to the eye at the design load.

In view of the semi-reinforced (TP-NSR) specimens, the tensile stress at $10 \mathrm{~mm}$ reached $1.28 \mathrm{MPa}$ and 1.37 $\mathrm{MPa}$, which correspond to a practically identical difference in the stress with respect to the mix ratio in steel fiber. The stress reduced at $60 \mathrm{~mm}$ to become a compressive stress of $2.96 \mathrm{MPa}$ for $1 \%$ of steel fiber and a compressive stress of $1.61 \mathrm{MPa}$ for $2 \%$ of steel fiber. These compressive stresses increased to $4.65 \mathrm{MPa}$ and 1.48 $\mathrm{MPa}$ at $110 \mathrm{~mm}$. These specimens (TP-NSR) exhibited thus larger difference between the tensile and compressive stresses than the non-reinforced (NTP-NSR) specimens.

In the case of the fully reinforced (TP-SR) specimens, tensile stresses of $0.19 \mathrm{MPa}$ and $0.13 \mathrm{MPa}$ similar to those of the non-reinforced specimens were measured at $10 \mathrm{~mm}$. These stresses became compressive stresses of 2.99 $\mathrm{MPa}$ and 2.54 MPa at $60 \mathrm{~mm}$ and $2.90 \mathrm{MPa}$ and $3.16 \mathrm{MPa}$ at $110 \mathrm{~mm}$.

Except for the specimen with $1 \%$ of steel fiber (NTP-NSR-1), all the non-reinforced (NTP-NSR) specimens showed a distribution of tensile stresses at $10 \mathrm{~mm}$ that turned onto a distribution of compressive stresses as much as the location moved toward the center of the specimens. The different stress distribution observed for the specimen with $1 \%$ of steel fiber (NTP-NSR-1) can be explained by the eventual occurrence of cracks at the measurement spot.

\subsubsection{Longitudinal Edge Tensile Stresses}

Figure 7 plots the variation of the edge tensile stress along the length of the specimens. The stress distribution was measured by longitudinal gages disposed at distances of $10 \mathrm{~mm}, 0.3 b, 0.5 b$ and $1.0 b$ from the top. Table 6 arranges the corresponding values of the longitudinal edge tensile stress. 


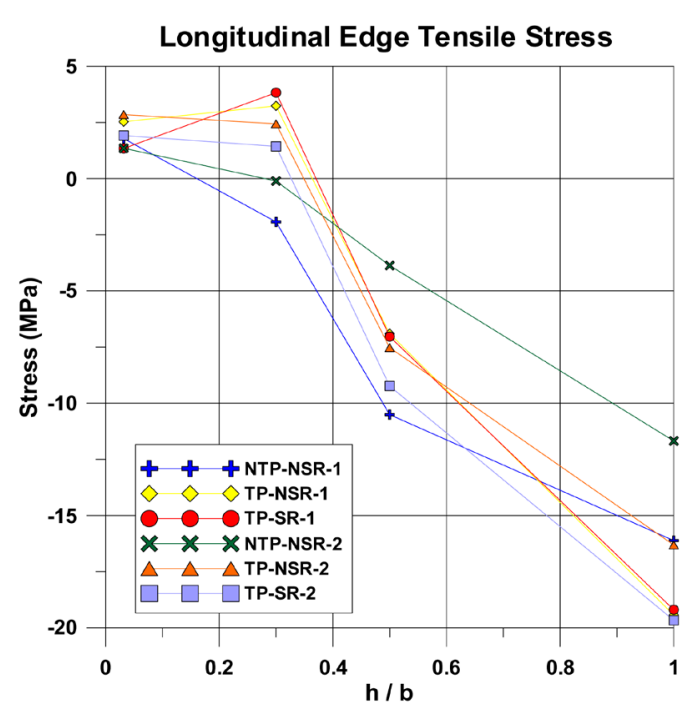

Figure 7. Longitudinal edge tensile stress according to applied load.

Table 6. Longitudinal edge tensile stresses at diverse locations (in MPa).

\begin{tabular}{ccccccc}
\hline$h / b$ & NTP-NSR-1 & TP-NSR-1 & TP-SR-1 & NTP-NSR-2 & TP-NSR-2 & TP-SR-2 \\
\hline 0.03 & 1.78 & 2.53 & 1.34 & 1.35 & 2.85 & 1.92 \\
0.3 & -1.93 & 3.24 & 3.83 & -0.11 & 2.44 & 1.43 \\
0.5 & -10.51 & -6.90 & -7.04 & -3.87 & -7.53 & -9.24 \\
1.0 & -16.12 & -19.43 & -19.19 & -11.68 & -16.31 & -19.66 \\
\hline
\end{tabular}

The comparison of the non-reinforced (NTP-NSR) specimens with $1 \%$ and $2 \%$ of steel fiber shows that tensile stresses of $1.78 \mathrm{MPa}$ and $1.35 \mathrm{MPa}$ were measured at $10 \mathrm{~mm}$, compressive stresses of $1.93 \mathrm{MPa}$ and 0.11 $\mathrm{MPa}$ were observed at $0.3 \mathrm{~b}$ and increased up to $10.51 \mathrm{MPa}$ and $3.87 \mathrm{MPa}$ at $0.5 \mathrm{~b}$. The large difference in the stress at $0.5 b$ according to the mix ratio of steel fiber can be explained by the occurrence of micro-cracks invisible to the eye similarly to the bursting force. Compressive stress of $16.12 \mathrm{MPa}$ and $11.68 \mathrm{MPa}$ occurred at $1.0 \mathrm{~b}$. Following, it was observed that the non-reinforced (NTP-NSR) specimens with 1\% and 2\% of steel fiber exhibited a distribution of tensile stresses near the top which turned onto a distribution of compressive stresses when moving down along the length of the specimens.

For the semi-reinforced (TP-NSR) specimens, tensile stresses of $2.53 \mathrm{MPa}$ (1\% of steel fiber) and $2.85 \mathrm{MPa}$ ( $2 \%$ of steel fiber) were measured at $10 \mathrm{~mm}$ and remained tensile stresses with respective values of $3.24 \mathrm{MPa}$ and 2.44 MPa at $0.3 b$ differently to the non-reinforced specimens. At $0.5 b$, both specimens (TP-NSR-1 and TPNSR-2) showed steep gradient and presented a distribution of compressive stresses of 6.90 MPa and 7.53 MPa which increased to become $19.43 \mathrm{MPa}$ and $19.66 \mathrm{MPa}$ at $1.0 \mathrm{~b}$.

In view of the fully reinforced (TP-SR) specimens, tensile stress distribution was observed at $10 \mathrm{~mm}$ with values of $1.34 \mathrm{MPa}$ and $1.92 \mathrm{MPa}$ as well as at $0.3 \mathrm{~b}$ with values of $3.83 \mathrm{MPa}$ and $1.43 \mathrm{MPa}$ similarly to the semi-reinforced (TP-NSR) specimens. The stress changed onto compressive stress of 19.19 MPa and 19.99 $\mathrm{MPa}$ at $0.5 b$.

All the three types of specimens experienced tensile stress near the top, which changed to become very large compressive stress when moving downward along the length of the specimens.

\subsubsection{Longitudinal Displacement of Specimens}

A total of 4 displacement transducers (DT) were installed on the left-hand side, right-hand side, top and bottom of the specimens to measure their overall displacement. Figure 8 arranges the longitudinal displacement meas- 
ured in each type of specimen and the corresponding values are listed in Table 7.

The non-reinforced specimens with $1 \%$ of steel fiber (NTP-NSR-1) experienced a longitudinal displacement of $0.151 \mathrm{~mm}$ at maximum load of $3300 \mathrm{kN}$ whereas the same specimens with $2 \%$ of steel fiber (NTP-NSR-2) experienced a longitudinal displacement of $0.174 \mathrm{~mm}$ at $3800 \mathrm{kN}$. The slight difference in the displacement can be attributed to the difference in the size of the applied loads.

Longitudinal displacements of $0.122 \mathrm{~mm}$ and $0.142 \mathrm{~mm}$ were measured under maximum load of $3800 \mathrm{kN}$ for the semi-reinforced (TP-NSR) specimens with $1 \%$ and $2 \%$ of steel fiber. The longitudinal displacements measured in the fully reinforced (TP-SR) specimens with $1 \%$ and $2 \%$ of steel fiber reached respectively $0.153 \mathrm{~mm}$ and $0.143 \mathrm{~mm}$ under maximum load of $3900 \mathrm{kN}$.

The three types of specimens exhibited a difference of about $0.01 \mathrm{~mm}$ in their displacements according to the mix ratio of steel fiber when subjected to similar loading, which indicates that the mix ratio of steel fiber has poor effect on the displacement.

\subsection{Failure Mode of Specimens}

\subsubsection{Non-Reinforced (NTP-NSR) Specimens}

Visible cracks could not be observed in all the non-reinforced specimens until the limit test load of $2002 \mathrm{kN}$ $\left(F_{\text {prg }}\right.$ ). The first visible cracks occurred at load beyond $3000 \mathrm{kN}$ in the specimens with $2 \%$ of steel fiber (NTPNSR-2). Moreover, early cracking initiated in the portion between $0.2 b$ and $0.7 b$ from the top in the specimens with $1 \%$ of steel fiber (NTP-NSR-1) and in the portion between $0.3 b$ and $0.5 b$ from the top in the specimens with $2 \%$ of steel fiber (NTP-NSR-2). The cracks in both specimens propagated downward from the top to the bottom. The cracks at the top propagated along the top face toward the part below the loading plate. The length of the cracks propagating downwards reached 2.2 times (1\% of steel fiber) and 1.5 times (2\% of steel fiber) the cross sectional width with respect to the mix ratio of steel fiber.

At the whole, numerous cracks developed during placing at the top face of the form where concrete is exposed to the air. The crack width measured by the crack gages reached maximum $0.6 \mathrm{~mm}$ and $0.2 \mathrm{~mm}$ according to the mix ratio of steel fiber. Figure 9 shows a photograph of the typical cracking pattern of a failed non-reinforced specimen and the corresponding distribution of the cracks.

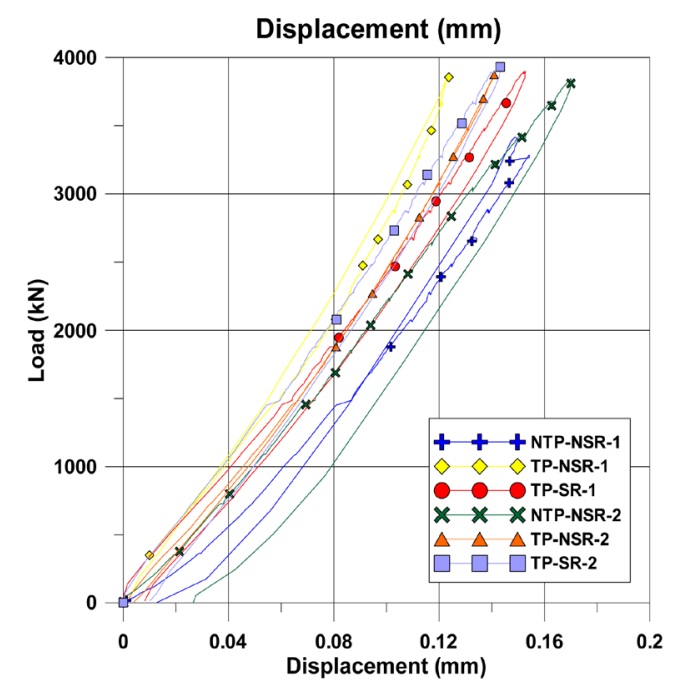

Figure 8. Longitudinal displacement according to applied load.

Table 7. Longitudinal displacements (in mm).

\begin{tabular}{cccccc}
\hline NTP-NSR-1 & TP-NSR-1 & TP-SR-1 & NTP-NSR-2 & TP-NSR-2 & TP-SR-2 \\
\hline 0.151 & 0.122 & 0.153 & 0.174 & 0.142 & 0.143 \\
\hline
\end{tabular}




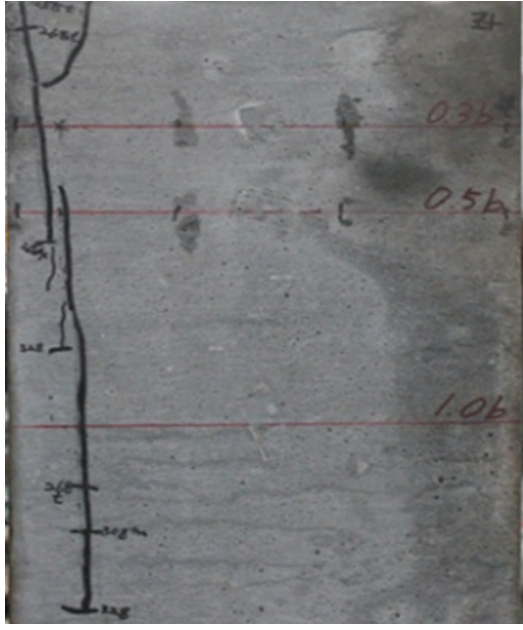

(a) Cracking of specimen

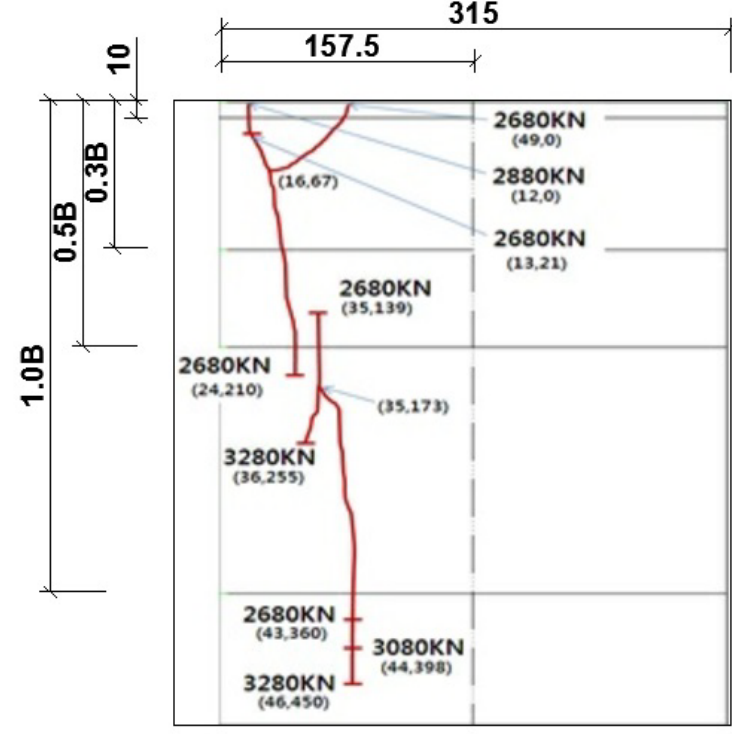

(b) Crack pattern

Figure 9. Cracking pattern of non-reinforced (7ST-NTP-NSR-1) specimen.

\subsubsection{Semi-Reinforced (TP-NSR) Specimens}

Differently from the non-reinforced (NTP-NSR) specimens, early cracking occurred at $1900 \mathrm{kN}$ for the semireinforced specimens with $1 \%$ of steel fiber (TP-NSR-1) and at $2080 \mathrm{kN}$ for the semi-reinforced specimens with $2 \%$ of steel fiber (TP-NSR-2), which did not show visible cracks until $2002 \mathrm{kN}$. In addition, relatively long cracks propagated in the portion between $0.3 b$ and $0.9 b$ from the top face in the semi-reinforced specimens with $1 \%$ of steel fiber (TP-NSR-1) whereas the cracks in the semi-reinforced specimens with $2 \%$ of steel fiber (TP-NSR-2) propagated in the portion between $0.2 b$ and $0.5 b$ from the top face. All the cracks in both specimens propagated downward from the top to the bottom. The cracks at the top propagated along the top face toward the monolithic connection between concrete and the loading plate. The downward cracks propagated identically to those of the non-reinforced specimens and reached lengths of 1.7 times ( $1 \%$ of steel fiber) and 1.3 times ( $2 \%$ of steel fiber) the cross sectional width with respect to the mix ratio of steel fiber. The shorter propagation of the cracks compared to the non-reinforced specimens can be explained by the larger number of cracks detected on the anchored specimens. Moreover, the crack width measured by the crack gages reached maximum $0.53 \mathrm{~mm}$ and $0.3 \mathrm{~mm}$ according to the mix ratio of steel fiber. Similarly to the pattern observed in the non-reinforced specimens, numerous cracks developed during placing at the top face of the form. Figure 10 presents the photograph of the cracking pattern of a failed semi-reinforced (TP-NSR) specimen and the corresponding distribution of the cracks.

\subsubsection{Fully Reinforced (TP-SR) Specimens}

Similarly to the non-reinforced specimens, visible cracks could not be observed at test load of $2002 \mathrm{kN}$ in the fully reinforced (TP-SR) specimens with $1 \%$ and $2 \%$ of steel fiber and became visible at $2080 \mathrm{kN}$ for $1 \%$ of steel fiber (TP-SR-1) and $2280 \mathrm{kN}$ for $2 \%$ of steel fiber (TP-SR-2). Early cracking occurred in the portion between $0.3 b$ and $0.5 b$ from the top face in both mix ratios. Similarly to the semi-reinforced (TP-NSR) specimens, the cracks propagated downward from the top to the bottom. The upward cracks developed in smaller number than the semi-reinforced specimens and the downward cracks propagated along lengths reaching 0.9 times (1\% of steel fiber) and 0.8 times ( $2 \%$ of steel fiber) the cross sectional width with respect to the mix ratio of steel fiber. The shorter propagation length of the cracks than the other types of specimens can be explained by the presence of the confinement reinforcement. Moreover, the maximum crack width measured by the crack gages varied between $0.13 \mathrm{~mm}$ and $0.15 \mathrm{~mm}$ according to the mix ratio of steel fiber. Here also, numerous cracks developed during placing at the top face of the form. Figure 11 presents the photograph of the cracking pattern of a failed fully reinforced (TP-SR) specimen and the corresponding distribution of the cracks. 


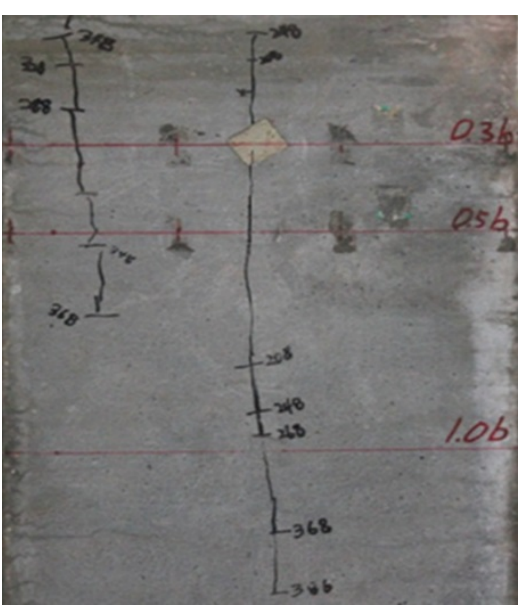

(a) Cracking of specimen

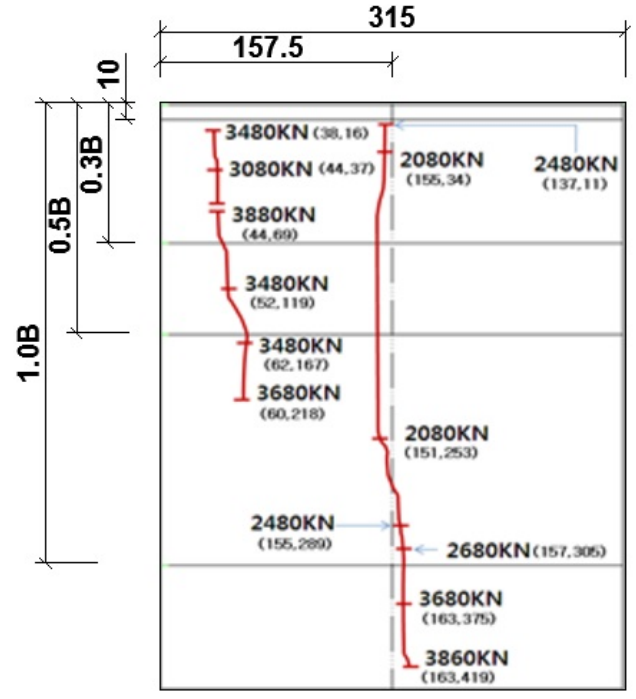

(b) Crack pattern

Figure 10. Cracking pattern of semi-reinforced (7ST-TP-NSR-1) specimen.

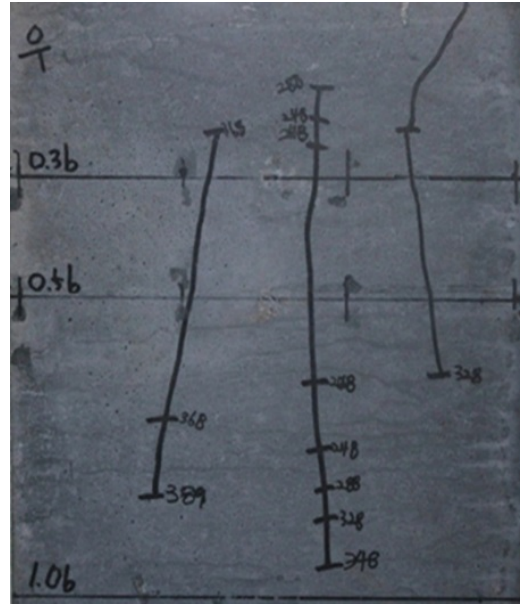

(a) Cracking of specimen

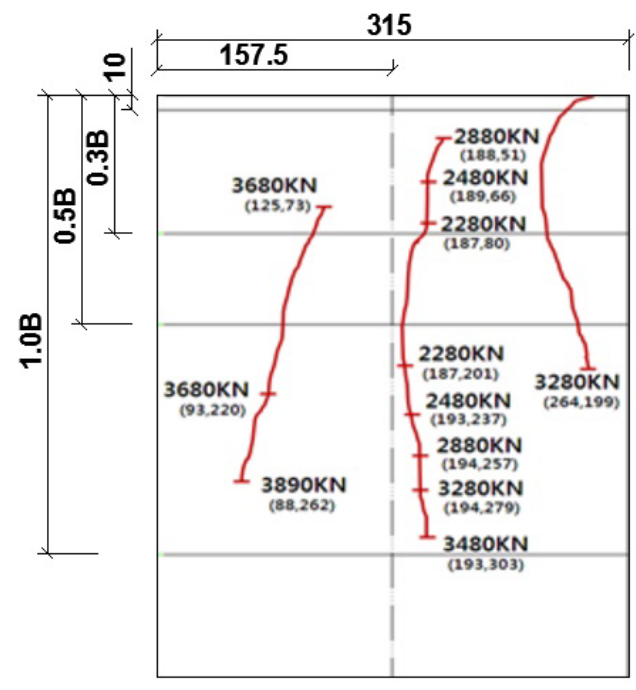

(b) Crack pattern

Figure 11. Cracking pattern of fully reinforced (7ST-TP-SR-1) specimen.

\section{Conclusions}

This study performed a load transfer test on PS anchorages using UHPC in post-tensioned members to evaluate experimentally their mechanical behaviors. To that goal, three types of specimen with different types of reinforcement, which are non-reinforced specimens without anchorage and spiral reinforcement (NTP-NSR), specimens equipped with anchorage but without spiral reinforcement (TP-NSR) and specimens with anchorage and spiral reinforcement (TP-SR), and with mix ratio of steel fiber of $1 \%$ and $2 \%$ were manufactured and subjected to load transfer test so as to observe the distributions of the bursting stress, spalling stress and longitudinal edge stress in the specimens according to the type of reinforcement. The longitudinal displacement and cracking pattern of the specimens were also compared. The results summarized hereafter are expected to provide basic data to be reflected in the design of PS anchorages in post-tensioned members using UHPC.

1) The maximum bursting stress occurred longitudinally between $0.3 b$ and $0.5 b$ ( $b=$ width of cross section) with a pattern similar to that predicted through finite element analysis. Beyond the transient region, stresses of 
constant values were seen to be distributed within a zone extending over a region corresponding to the cross sectional dimensions. This stress distribution exhibited pattern similar to that of the PS anchorage of post-tensioned members using ordinary concrete.

2) The spalling stress developed as tensile stress around the edge and changed onto compressive stress when moving toward the center of the specimens but all the stresses showed relatively small values. Since the cracking pattern of anchorage zone using UHPC appeared to be similar to that when using ordinary concrete, it could be assessed that larger resistance to the spalling stress could be achieved through the use of UHPC owing to its high tensile strength.

3) The design of PS anchorage using ordinary concrete was complicated due to the need to arrange reinforcement steel longitudinally and laterally at the edge to resist the edge tensile stress. However, the use of UHPC was seen to satisfy all the load-bearing capacity criteria proposed by the European ETAG-013 provisions owing to the bridging effect of the steel fibers even without use of anchorage and particular confinement steel.

4) Similarly to the cracking pattern of ordinary concrete, the cracks of the specimens propagated downward from the top to the bottom. The downward cracks propagated along lengths up to twice the cross sectional dimensions. The crack widths satisfied the test criteria and remained very small with maximum value of $0.6 \mathrm{~mm}$ after completion of the tests.

5) This study performed load transfer test on PS anchorage using UHPC and verified the ability of the PS anchorages to resist tensile stresses without anchor and particular confinement reinforcement owing to the high strength of UHPC. The results are promising for further reduction of the cross sectional dimensions and simplification of the reinforcement arrangement details in the design of PS anchorage applying UHPC.

\section{Acknowledgements}

This research was supported by a grant (13SCIPA02) from a Smart Civil Infrastructure Research Program funded by Ministry of Land, Infrastructure and Transport (MOLIT) of Korea government and Korea Agency for Infrastructure Technology Advancement (KAIA).

\section{References}

[1] Graybeal, B. (2011) Ultra-High Performance Concrete. Technote, FHWA-HRT-11-038, Federal Highway Administration, McLean.

[2] Russell, H.G. and Graybea, B.A. (2013) Ultra-High Performance Concrete: A State-of-the-Art Report for the Bridge Community, FHWA-HRT-13-060.

[3] Toutlemonde, F., et al. (2009) Efforts et Acquis de Recherchesur les BFUP depuis 2002 en vue del'Actualisation des Recommandations de l'AFGC. (An Overview of Research Advances from 2002 Concerning UHPFRC, in View of Updating AFGC Recommendations). Proceedings of the International Workshop on Ultra High Performance Fibre Reinforced Concrete-Designing and Building with UHPFRC: State of the Art Development, Marseille, 17-19 November 2009, AFGC/fib, Paper 5.3.4.

[4] Resplendino, J. (2009) Bétons Fibrés Ultra Performant (BFUP)—Les Nouvelles Recommandations AFGC. (Updated AFGC Recommendations). Proceedings of the International Workshop on Ultra High Performance Fibre Reinforced Concrete-Designing and Building with UHPFRC: State of the Art Development, Marseille, 17-19 November 2009, AFGC/fib, Paper 6.1.1.

[5] Schmidt, M. (2012) Sustainable Building with Ultra-High-Performance Concrete (UHPC)—Coordinated Research Program in Germany. In: Schmidt, M., Fehling, E., Glotzbach, C., Fröhlich, S. and Piotrowski, S., Eds., Proceedings of Hipermat 2012 3rd International Symposium on UHPC and Nanotechnology for High Performance Construction Materials, Kassel University Press, Kassel, 17-25.

[6] Japan Society of Civil Engineers (JSCE) (2006) Recommendations for Design and Construction of Ultra High Strength Fiber Reinforced Concrete Structures (Draft). JSCE Guidelines for Concrete No. 9.

[7] Kim, B.-S., et al. (2012) R\&D Activities and Application of Ultra High Performance Concrete to Cable-Stayed Bridges. In: Schmidt, M., Fehling, E., Glotzbach, C., Fröhlich, S. and Piotrowski, S., Eds., Proceedings of Hipermat $20123 r d$ International Symposium on UHPC and Nanotechnology for High Performance Construction Materials, Kassel University Press, Kassel, 865-872.

[8] Toutlemonde, F., Renaud, J.-C., Lauvin, L., Behloul, M., Simon, A. and Vildare, S. (2007) Testing and Analysing Innovative Design of UHPFRC Anchor Blocks for Post-Tensioning Tendons. 6th International Conference on Fracture Mechanics of Concrete and Concrete Structures (FRAMCOS-6), Catania, 17-22. 
[9] EOTA (2002) ETAG-013: Guideline for European Technical Approval of Post-Tensioning Kits for Prestressing of Structures.

[10] Ministry of Land, Transport and Maritime Affairs (2010) Korean Highway Bridge Design Code (in Korean).

[11] Kim, J.S., Kwark, J.W., Joh, C.B. and Choi, Y.S. (2011) Bursting Forces of Anchorage Zone in UHPC Post-Tensioned Members Considering the Size of Anchorage Plates. Conference of KSCE, 30, 1388-1391 (in Korean). 